\title{
Gestão democrática da educação: o que revelam os dados do projeto da rede estadual paulista?
}

\author{
Democratic management of education: what do the data of the São Paulo state \\ network project reveal?
}

Gestión democrática de la educación: ¿qué revelan los datos del proyecto de la red estatal de São Paulo?

RICARDO ALEXANDRE MARANGONI
https://orcid.org/0000-0002-4080-0673
Universidade Cidade de São Paulo
Programa de Pós-Graduação em Educação
Departamento de Educação
São Paulo, SP, Brasil
ÂNGELO RICARDO DE SOUZA
https://orcid.org/0000-0002-0246-3207
Universidade Federal do Paraná
Faculdade de Educação

Paraná, PR, Brasil

\begin{abstract}
Resumo: Este artigo apresenta as representações de discentes, docentes, gestores, servidores, pais ou responsáveis sobre a gestão democrática da escola pública paulista. A partir dos dados de um projeto, implementado no período de 2016 a 2017 pela Secretaria da Educação do Estado de São Paulo, analisouse como as práticas declaradas vêm contribuindo (ou não) com o processo de democratização da gestão das escolas públicas da rede estadual de ensino. O presente Artigo contou com o aporte teórico de autores como Draibe (2001), Souza (2007a, 2007b, 2012, 2016, 2019), Touraine (1996), entre outros, para relacionar o contexto macro das políticas e o micro, por meio das representações dos sujeitos. Aproximando-se da teoria das representações sociais, proposta por Moscovici $(1961 / 2012)$, a pesquisa foi realizada a partir do tensionamento entre os aportes legais, teóricos e os dados captados no projeto analisado. As conclusões apontam para a necessidade de se questionar as condições concretas e objetivas por meio das quais a gestão democrática (não) se realiza.
\end{abstract}

Palavras-chave: Gestão Democrática; Escola Pública; Políticas Educacionais; Representações. 


\begin{abstract}
This article presents the representations of students, teachers, principals, servants, parents, or guardians about the public school democratic administration at São Paulo, Brazil. Based on data from a project implemented between 2016 and 2017 by the São Paulo State Department of Education, the work analyzed how the declared practices have contributed (or not) to the process of democratization of public school administration. The research was based on the theoretical contributions of authors such as Draibe (2001), Soura (2007a, 2007b, 2012, 2016, 2019), Touraine (1996), among others, looking for the link between the macro and micro policies context, through the subjects' representations. Approaching the social representations theory, proposed by Moscovici (1961/2012), the research was carried out from the tension including the legal and theoretical contributions and the analyzed project data. The conclusions point to the need to question the concrete and objective conditions under which democratic administration (does not) take place.
\end{abstract}

Keywords: Democratic Administration; Public School; Educational Policies; Representations.

Resumen: Este articulo presenta las representaciones de estudiantes, maestros, directivos, funcionarios, padres o tutores sobre la gestión democrática de la escuela pública de São Paulo. A partir de los datos de un proyecto implementado en el período de 2016 a 2017 por el Departamento de Educación del Estado de São Paulo, se analizó cómo las prácticas declaradas han contribuido (o no) al proceso de democratización de la gestión de las escuelas públicas en la red de enseñanza del estado. Se contó con el aporte teórico de autores como Draibe (2001), Souza (2007a, 2007b, 2012, 2016, 2019), Touraine (1996), entre otros, para relacionar el macrocontexto de las politicas y el micro, a través de las representaciones de los sujetos. Acercándose a la teoría de las representaciones sociales, propuesta por Moscovici (1961/2012), la investigación se realizó a partir de la tensión entre las aportaciones jurídicas y teóricas y los datos captados en el proyecto analizado. Las conclusiones apuntan para la necesidad de cuestionar las condiciones concretas y objetivas a través de las cuales (no) tiene lugar la gestión democrática.

Palabras clave: Gestión democrática; Escuela pública; Políticas educativas; Representaciones.

\title{
INTRODUÇÃO
}

Esta pesquisa tem como objetivo investigar as representações de alunos, pais/responsáveis, professores, gestores, servidores e sociedade civil sobre a gestão democrática (GD) da escola pública paulista, tendo como base os dados obtidos de um projeto intitulado Gestão Democrática da Educação, implementado no período de 2016 a 2017 pela Secretaria da Educação do Estado de São Paulo (SEDUC/SP). O referido projeto aponta, em sua justificativa, o propósito de avançar no processo democrático em espaços de decisão e deliberação existentes na escola, tais como o Conselho de Escola (CE), a Associação de Pais e Mestres (APM) e o Grêmio Estudantil (GE) (SÃO PAULO, 2018). 
O presente texto está organizado em três momentos. $\mathrm{O}$ primeiro apresenta uma descrição do projeto, no qual debruçamo-nos sobre a proposição e estrutura desenhada nesta ação da SEDUC/SP e por ela mesma declarada como em favor da ampliação da participação dos processos de gestão das escolas públicas estaduais paulistas.

Em um segundo momento, descrevemos o percurso metodológico da pesquisa, tendo em vista a origem e forma de tratamento dos dados.

E, finalmente, promovemos a exposição daqueles dados da pesquisa e levantamos uma discussão sobre o projeto paulista, apontando a necessidade de observação e questionamento das condições objetivas e concretas para a realização da gestão escolar democrática.

\section{O PROJETO DE GESTÃO DEMOCRÁTICA DA REDE ESTADUAL PAULISTA}

Segundo a SEDUC/SP, a discussão da modernização da GD nas escolas públicas paulistas vem sendo realizada por meio da união de alunos, pais/ responsáveis, professores, gestores, servidores e sociedade civil, no esforço de aperfeiçoar os espaços de decisão e deliberação da escola, tais como o CE, a APM e o GE (SÃO PAULO, 2018).

Dessa maneira, a SEDUC/SP criou, em maio de 2016, o Projeto Gestão Democrática da Educaşão com o objetivo de ampliar a cultura democrática das escolas e de sua comunidade, por meio da participação dos sujeitos nos órgãos colegiados (SÃO PAULO, 2018).

Complementarmente, e para além dos dados apresentados pelo site da SEDUC/SP, encontramos mais dois sites (www.inspirare.org.br / www.porvir. org) que nos ajudaram a compreender o projeto. O Instituto Inspirare, do qual o Porvir faz parte, declarou ser parceiro da Secretaria no desenvolvimento do projeto. O que nos chamou a atenção é a falta dessa informação no próprio site da Secretaria, o que revela um primeiro incômodo: por que a SEDUC/SP ocultou o seu parceiro (Instituto Inspirare) no site oficial? Mais adiante, vamos expor nosso entendimento sobre essa questão.

Fazem parte do projeto todas as 91 Diretorias de Ensino do Estado de São Paulo. Apenas, a de Carapicuíba, não teve os dados sobre a categoria GD apresentados no site da SEDUC/SP.

O projeto foi desenvolvido em quatro etapas: Diagnóstico, Local, Regional e Estadual. 
A primeira etapa (diagnóstico) ocorreu de agosto de 2016 a janeiro de 2017, e foi marcada por dois momentos específicos e complementares: o primeiro, que data de 20 de julho a 30 de outubro de 2016, no qual ocorreram ações relacionadas à apresentação e à construção do projeto; o segundo, que data de 31 de outubro a 18 de dezembro de 2016, no qual ocorreu a disponibilização do questionário do projeto à sociedade.

Foi em 20 de julho de 2016, que a Rede de Ensino do Estado de São Paulo teve acesso ao Projeto Gestão Democrática da Educação, por meio de uma videoconferência. No mês de agosto, sucederam-se as ações: 30 pessoas, chamadas de facilitadores, foram capacitadas e responsáveis pelos grupos de escuta em seus polos; apresentação da metodologia dos grupos de escuta à Rede Estadual de Ensino; realização de 105 grupos de escuta, envolvendo cerca de 2.700 participantes da comunidade escolar e 1.500 escolas; apresentação do projeto à sociedade; em 30 de agosto, foi disponibilizado um box (formulário de contribuições) no site da SEDUC/SP, para que os alunos, pais/responsáveis, professores, gestores, servidores e a sociedade civil pudessem participar e contribuir com o desenvolvimento do projeto. Até 8 de novembro de 2016, foram enviadas 1.412 sugestões para o projeto (SÃO PAULO, 2018).

A partir das informações coletadas pelos grupos de escuta, foi construído o questionário. Este organizou-se em três blocos: o primeiro, com questões que envolvem a caracterização ou perfil dos respondentes; o segundo, com questões que contemplam a GD na escola; o terceiro, com questões que se relacionam aos espaços de participação (CE, APM e GE). Sua aplicação ocorreu entre 31 de outubro e 18 de dezembro de 2016 (SÃO PAULO, 2018).

$\mathrm{Na}$ segunda etapa, chamada de local, os dados coletados (a partir do questionário) foram divulgados às escolas, e serviram para fomentar o debate em cada unidade escolar com a comunidade. Segundo a SEDUC/SP, 4.684 escolas (93\%) participaram da atividade. Ocorreu em maio de 2017.

O resultado da etapa anterior subsidiou a discussão da etapa regional, que ocorreu no âmbito das Diretorias de Ensino. Após o debate, cada Diretoria inseriu 15 propostas na Secretaria Escolar Digital para votação. Foram 1.341 propostas cadastradas, das quais a comunidade escolar elegeu 10 propostas para representar cada Diretoria. Ao final desta etapa, as sugestões foram sistematizadas em um documento matriz com 908 propostas selecionadas. O debate nas Diretorias aconteceu no segundo semestre de 2017. 
Com os dados organizados da terceira etapa (regional), ocorreu em dezembro de 2017 a quarta etapa, um debate em nível estadual ${ }^{1}$. Participaram do encontro 240 pessoas dos segmentos: alunos, pais/responsáveis, professores, gestores, funcionários e técnicos de Diretorias de Ensino. Segundo a SEDUC/SP, havia representantes de apenas 15 Diretorias e a escolha dos indicados levou em conta a participação ativa no projeto.

As contribuições (908 propostas) foram analisadas e agrupadas, para posterior, elaboração de um projeto de Lei. A Secretaria também afirmou que as contribuições serão utilizadas para o fortalecimento da democracia nas escolas. $\mathrm{O}$ projeto de Lei ainda não foi submetido à consulta pública e enviado à Assembleia Legislativa para aprovação até a data de finalização deste artigo, abril de 2020.

\section{PERCURSO METODOLÓGICO}

A pesquisa que originalmente gerou este artigo está organizada em três etapas específicas e complementares: (i) revisão de literatura²; (ii) descrição do projeto; (iii) sistematização e discussão das respostas declaradas no questionário de 2016, desenhando um cenário descritivo-interpretativo em âmbito estadual.

Os dados utilizados para a parte empírica da pesquisa estão sistematizados no site da SEDUC/SP. Neste trabalho apresentamos a análise referente aos dados da primeira etapa (Diagnóstico) do projeto Gestão Democrática da Educaşão.

Assinalamos, também, que não há pretensão de entrar no debate em torno do conceito de representação social, mas não podemos nos furtar de apontar que a teoria (MOSCOVICI, 1961/2012) vem construindo um caminho promissor no estudo de políticas educacionais.

\section{O INSTRUMENTO DE COLETA DE DADOS UTILIZADO PELA SEDUC/SP}

Utilizando um questionário de dezenove questões, a SEDUC/SP coletou os dados da primeira etapa do projeto (diagnóstico). Neste momento, serão apresentadas apenas as questões referentes ao perfil dos participantes e da categoria GD. Chamamos atenção para o fato de que existem outras questões, relativas às categorias GE, CE e APM. Apesar do reconhecimento da estreita conexão desses órgãos colegiados com a GD, por ora, analisaremos uma parte do questionário.

1 Os dados apresentados não estão disponíveis no site da SEDUC/SP. A última disponibilizou algumas informações por e-mail.

Para acessar esta discussão, ver Marangoni (2018). 
As questões ligadas ao perfil dos participantes estão organizadas nos quadros de 1 a 3 , a seguir:

\section{Quadro 1}

\begin{tabular}{|l|}
\hline Qual a sua relação com esta escola? \\
\hline A. Sou aluno \\
\hline B. Sou professor \\
\hline C. Integro a Equipe Gestora (diretor, vice-diretor, professor coordenador, GOE) \\
\hline D. Sou servidor (QAE / QSE) \\
\hline E. Sou familiar ou responsável por aluno \\
\hline F. Nenhuma das anteriores \\
\hline
\end{tabular}

Fonte: SEDUC/SP, 2018.

\section{Quadro 2}

\begin{tabular}{|l|}
\hline (Complemento Questão Anterior) Aluno - Tipo de Vínculo com a Escola \\
\hline A. Ensino Fundamental $-1^{\circ}$ a $5^{\circ}$ Ano \\
\hline B. Ensino Fundamental $-6^{\circ}$ a $9^{\circ}$ Ano \\
\hline C. Ensino Médio Diurno \\
\hline D. Ensino Médio Noturno \\
\hline E. EJA \\
\hline F. Não sou aluno / Outras categorias (Professor, Servidor, Responsável) \\
\hline
\end{tabular}

Fonte: SEDUC/SP, 2018.

\section{Quadro 3}

\begin{tabular}{|l|}
\hline Qual a sua faixa de idade? \\
\hline A. Menos de 11 anos \\
\hline B. 11 a 14 anos \\
\hline C. 15 a 19 anos \\
\hline D. 20 a 29 anos \\
\hline E. 30 a 39 anos \\
\hline F. 40 a 49 anos \\
\hline G. 50 a 59 anos \\
\hline H. Mais de 60 anos \\
\hline
\end{tabular}

Fonte: SEDUC/SP, 2018. 
Conforme podemos observar, as questões priorizaram a relação do participante com a escola, o tipo de vínculo com a escola e a faixa etária. A noção de quem é o grupo de respondentes, a partir destas variáveis, poderá justificar certas escolhas e o modo como pensam.

As questões relativas à GD estão organizadas nos quadros de 4 a 8 , a seguir:

\section{Quadro 4}

\begin{tabular}{|l|}
\hline Você faz parte de algum dos seguintes espaços de participação na escola? Qual(is)? \\
\hline A. Grêmio Estudantil \\
\hline B. Associação de Pais e Mestres \\
\hline C. Conselho de Escola \\
\hline D. Outra \\
\hline
\end{tabular}

Fonte: SEDUC/SP, 2018.

\section{Quadro 5}

\begin{tabular}{|l|}
\hline Na sua opinião, qual das alternativas abaixo melhor descreve a GD nas escolas? \\
\hline $\begin{array}{l}\text { A. Diálogo constante entre a equipe gestora (diretor, vice-diretor, professor coordenador) e todos que fazem parte da escola: } \\
\text { professores, servidores, alunos e familiares }\end{array}$ \\
\hline B. Participação de professores, servidores, alunos e familiares nas decisões e melhorias da escola \\
\hline C. Envolvimento efetivo de professores, servidores, alunos e familiares em grupos formais \\
\hline D. Quando professores, servidores, alunos e familiares se responsabilizam pela escola, com direitos e deveres compartilhados \\
\hline E. Uma combinação entre todas as anteriores \\
\hline F. Nenhuma das anteriores \\
\hline G. Não sei opinar
\end{tabular}

Fonte: SEDUC/SP, 2018.

\section{Quadro 6}

\begin{tabular}{|l|}
\hline Qual alternativa mais contribui para garantir uma GD na escola? \\
\hline A. Quando as opiniões de todos os participantes da comunidade escolar são escutadas e consideradas \\
\hline B. Quando as decisões na escola são tomadas em assembleias abertas com participação da comunidade escolar \\
\hline C. Quando as atividades de participação acontecem em horário em que todos podem participar, inclusive as famílias \\
\hline $\begin{array}{l}\text { D. Quando a comunidade escolar participa da definição da aplicação de como os recursos financeiros da escola devem ser } \\
\text { utilizados }\end{array}$ \\
\hline E. Uma combinação das anteriores \\
\hline F. Nenhuma das anteriores \\
\hline G. Não sei opinar \\
\hline
\end{tabular}

Fonte: SEDUC/SP, 2018. 


\section{Quadro 7}

\begin{tabular}{|l|l|l|l|l|}
\hline $\begin{array}{l}\text { Na sua opinião, em que medida a GD pode melhorar os } \\
\text { seguintes aspectos do dia a dia da sua escola? }\end{array}$ & $\begin{array}{c}\text { Pode } \\
\text { melhorar } \\
\text { muito }\end{array}$ & $\begin{array}{c}\text { Pode } \\
\text { melhorar um } \\
\text { pouco }\end{array}$ & $\begin{array}{c}\text { Não pode } \\
\text { melhorar em } \\
\text { nada }\end{array}$ & $\begin{array}{c}\text { Não sei } \\
\text { opinar }\end{array}$ \\
\hline A. A inclusão e o respeito às diferenças entre as pessoas & & & & \\
\hline B. A motivação dos alunos para estudar & & & & \\
\hline $\begin{array}{l}\text { C. A motivação dos alunos para participar do dia a dia da } \\
\text { escola }\end{array}$ & & & & \\
\hline D. A aprendizagem dos alunos & & & & \\
\hline $\begin{array}{l}\text { E. O cuidado de professores, servidores, alunos e familiares } \\
\text { com a escola }\end{array}$ & & & & \\
\hline F. O envolvimento de todos no projeto pedagógico da escola & & & & \\
\hline $\begin{array}{l}\text { G. A colaboração de todos na solução dos problemas da } \\
\text { escola }\end{array}$ & & & & \\
\hline H. A aproximação entre as familias e a escola & & & & \\
\hline $\begin{array}{l}\text { I. A preparação dos alunos para a cidadania e para a } \\
\text { participação em processos democráticos }\end{array}$ & & & & \\
\hline
\end{tabular}

Fonte: SEDUC/SP, 2018.

\section{Quadro 8}

\begin{tabular}{|c|c|c|c|c|}
\hline $\begin{array}{l}\text { Pensando no que contribui com a GD, você diria isso } \\
\text { sobre a sua escola? }\end{array}$ & Com certeza & $\begin{array}{l}\text { Mais ou } \\
\text { menos }\end{array}$ & Não diria & $\begin{array}{l}\text { Não sei } \\
\text { opinar }\end{array}$ \\
\hline \multicolumn{5}{|l|}{ A. As pessoas sabem o que é democracia } \\
\hline \multicolumn{5}{|l|}{$\begin{array}{l}\text { B. As pessoas se preocupam em decidir e fazer o que é } \\
\text { melhor para todos }\end{array}$} \\
\hline \multicolumn{5}{|l|}{ C. Os alunos têm orgulho, cuidam e participam da escola } \\
\hline \multicolumn{5}{|l|}{$\begin{array}{l}\text { D. A equipe gestora e os professores escutam e valorizam a } \\
\text { opinião dos alunos }\end{array}$} \\
\hline \multicolumn{5}{|l|}{$\begin{array}{l}\text { E. A equipe gestora e os professores da escola ouvem e } \\
\text { estimulam a participação das famílias dos alunos }\end{array}$} \\
\hline \multicolumn{5}{|l|}{$\begin{array}{l}\text { F. As familias têm interesse em participar da escola e da vida } \\
\text { escolar dos alunos }\end{array}$} \\
\hline \multicolumn{5}{|l|}{$\begin{array}{l}\text { G. Os professores se interessam em participar das decisões } \\
\text { tomadas na escola }\end{array}$} \\
\hline \multicolumn{5}{|l|}{$\begin{array}{l}\text { H. A escola promove atividades em parceria com outras } \\
\text { organizações do bairro }\end{array}$} \\
\hline \multicolumn{5}{|l|}{$\begin{array}{l}\text { I. As pessoas da escola valorizam os espaços de participação, } \\
\text { como GE, CE e APM }\end{array}$} \\
\hline $\begin{array}{l}\text { J. A Secretaria de Educação cria condições para que a gestão } \\
\text { democrática aconteça na escola }\end{array}$ & & & & \\
\hline
\end{tabular}

Fonte: SEDUC/SP, 2018. 
Primeiramente, salientamos que a escolha do método e instrumento de coleta de dados utilizados pela SEDUC/SP, revela intenções. A estatística realizada, a partir da aplicação do questionário, tem o propósito de fornecer uma ideia geral sobre o que pensam os participantes a respeito da GD.

O questionário ${ }^{3}$ de múltipla escolha é um instrumento comum para identificar preferências de um grupo de pessoas. No entanto, vale lembrar que nem sempre as alternativas sugeridas condizem com a informação que o sujeito gostaria de dar. Observamos que a SEDUC/SP se utilizou das alternativas "outra", "nenhuma das anteriores" e "não sei opinar" para preencher essa demanda.

Outro aspecto a considerar refere-se ao suposto "tom neutro" adotado pela SEDUC/SP. Não há neutralidade; é oportuno dizer que esta condiciona a resposta do participante, enquadrando-o numa forma/fôrma de pensar que corresponde a sua própria. Dito isto, chamamos a atenção para o fato de as políticas públicas em geral, e as políticas educacionais em particular, desempenharem um importante papel na formação de (possíveis) representações. Logo, as representações são da SEDUC/SP, mas, também dos respondentes que concordaram com elas. Isso mostra que são intercambiáveis, não podendo polarizar dizendo que são destes e não daqueles.

Quanto às alternativas sugeridas para cada questão, afirmamos adentrar num campo complexo relacionado à questão semântica e à operacionalização do projeto Gestão Democrática da Educação. Adiantamo-nos asseverando que no cotidiano escolar, o discurso e a prática não se realizam de modo a fortalecer a GD. Ao contrário, nossas observações assistemáticas e alguns estudos (GANZELI, 2019) indicam o avanço da gestão gerencialista na Rede Pública Estadual Paulista, em especial nos últimos 25 anos (1995-2020), em que o PSDB está à frente do governo estadual.

Outro ponto importante a ser considerado é a utilização da escala Likert para as questões dos quadros 7 e 8 . A partir de uma afirmação, os participantes responderam às perguntas baseado em escalas com níveis de concordância ou discordância. Ressaltamos que esta escala é usada em uma pergunta fechada, com opções de respostas pré-preenchidas. A partir de um tema, tem-se a questão inicial e as questões de acompanhamento. $\mathrm{O}$ agrupamento de questões sobre um mesmo tema e a análise das respostas oferecem uma visão geral sobre o que pensam os respondentes e, sobretudo, o que pensam aqueles que organizaram

3 Ao final do questionário existem duas questões abertas que parecem ter sido desconsideradas pela SEDUC/SP. O nosso estudo limita-se a análise dos blocos I e II do questionário, denominados "caracterização" e "GD", respectivamente. 
o questionário, a SEDUC/SP. Desse modo, reiteramos que as políticas em ação, aliadas a outras dimensões, desempenham um importante papel na formação de (possíveis) representações.

\section{O QUE REVELAM OS DADOS?}

\section{CARACTERIZAÇÃO DOS PARTICIPANTES}

O questionário foi disponibilizado entre 30 de outubro e 18 dezembro de 2016. Ocorreu uma grande participação, sendo 448.593 no total.

Dos participantes, $71,4 \%$ foram alunos, $13,2 \%$ professores, $8,5 \%$ pais/ responsáveis, 3,6\% servidores e 3,4\% gestores.

Em relação a representatividade da Rede de Ensino de São Paulo, ou seja, o percentual de participantes em relação ao número total da Rede, observamos que $55 \%$ dos gestores participaram da pesquisa, seguido dos servidores com $32 \%$ e os professores com $29 \%$. Já os alunos, totalizaram apenas $9 \%$. Apesar do número de alunos ser maior, a representatividade deles foi menor.

Ao serem questionados sobre a sua relação com a escola, observamos que a maior parte dos alunos pertencem aos Anos Finais do Ensino Fundamental (46,2\%), seguido dos alunos do Ensino Médio, período diurno (34,2\%). Os demais foram do Ensino Médio noturno (9,4\%), Anos Iniciais do Ensino Fundamental (8\%) e EJA (2,1\%).

Quanto à faixa etária, observamos que os sujeitos de 15 a 19 anos de idade foram os que tiveram maior participação $(35,1 \%)$, seguido dos que possuem entre 11 e 14 anos de idade (31,7\%), entre 40 e 49 anos $(9,9 \%)$, entre 30 e 39 anos $(8,1 \%)$, entre 50 e 59 anos $(6,5 \%)$, abaixo de 11 anos (4,3\%), entre 20 e 29 anos $(3 \%)$ e acima de 60 anos $(1,3 \%)$. Esse dado revela a grande participação dos jovens na enquete realizada.

A tabela 1, demonstra o percentual de pessoas que participam dos espaços democráticos, a saber: CE, APM, GE e outros. 


\section{Tabela 1 - Respostas dos participantes}

\begin{tabular}{|l|c|c|}
\hline Você faz parte de algum dos seguintes espaços de participação na escola? Qual(is)? & Sim & Não \\
\hline A. Grêmio Estudantil & $8,4 \%$ & $91,6 \%$ \\
\hline B. Associação de Pais e Mestres & $11 \%$ & $89 \%$ \\
\hline C. Conselho de Escola & $17,3 \%$ & $82,7 \%$ \\
\hline D. Outros & $5,8 \%$ & $94,2 \%$ \\
\hline
\end{tabular}

Fonte: Adaptado da SEDUC/SP, 2018. A última forneceu os microdados.

Conforme podemos observar, a maioria dos respondentes afirmou não fazer parte dos espaços democráticos. O maior percentual atingiu 17,3\% de participação no CE, ainda considerado bastante baixo.

\section{DADOS RELACIONADOS À GESTÃO DEMOCRÁTICA}

A questão " $\mathrm{Na}$ sua opinião, qual das alternativas abaixo melhor descreve a GD nas escolas?", inaugura o segundo bloco, chamado de GD. A tabela 2 indica as respostas dos participantes.

\section{Tabela 2 - Respostas dos participantes}

\begin{tabular}{|l|c|}
\hline Na sua opinião, qual das alternativas abaixo melhor descreve a GD nas escolas? & $\begin{array}{c}\text { Quantidade de } \\
\text { Respondentes }\end{array}$ \\
\hline $\begin{array}{l}\text { A. Diálogo constante entre a equipe gestora (diretor, vice-diretor, professor coordenador) e todos que fazem } \\
\text { parte da escola: professores, servidores, alunos e familiares }\end{array}$ & $31 \%$ \\
\hline B. Participação de professores, servidores, alunos e familiares nas decisões e melhorias da escola & $13,9 \%$ \\
\hline C. Envolvimento efetivo de professores, servidores, alunos e familiares em grupos formais & $11,1 \%$ \\
\hline $\begin{array}{l}\text { D. Quando professores, servidores, alunos e familiares se responsabilizam pela escola, com direitos e } \\
\text { deveres compartilhados }\end{array}$ & $5,5 \%$ \\
\hline E. Uma combinação entre todas as anteriores & $24,5 \%$ \\
\hline F. Nenhuma das anteriores & $3,2 \%$ \\
\hline G. Não sei opinar & $10,8 \%$ \\
\hline
\end{tabular}

Fonte: Adaptado da SEDUC/SP, 2018. A última forneceu os microdados.

O diálogo constante entre a equipe gestora (diretor, vice-diretor, professor coordenador) e todos que fazem parte da escola: professores, servidores, alunos e familiares, foi, para os respondentes, a melhor descrição de GD (31\%). Salientamos que 10,8\% dos participantes não souberam ou quiseram se manifestar.

Para a próxima questão "Qual alternativa mais contribui para garantir uma GD na escola?”, obtivemos as respostas apontadas na tabela 3. 


\section{Tabela 3 - Respostas dos participantes}

\begin{tabular}{|l|c|}
\hline Qual alternativa mais contribui para garantir uma GD na escola? & $\begin{array}{c}\text { Quantidade de } \\
\text { Respondentes }\end{array}$ \\
\hline & $31 \%$ \\
\hline A. Quando as opiniões de todos os participantes da comunidade escolar são escutadas e consideradas & $33,6 \%$ \\
\hline $\begin{array}{l}\text { B. Quando as decisões na escola são tomadas em assembleias abertas com participação da comunidade } \\
\text { escolar }\end{array}$ & $12,1 \%$ \\
\hline $\begin{array}{l}\text { C. Quando as atividades de participação acontecem em horário em que todos podem participar, inclusive as } \\
\text { familias }\end{array}$ & $10,2 \%$ \\
\hline $\begin{array}{l}\text { D. Quando a comunidade escolar participa da definição da aplicação de como os recursos financeiros da } \\
\text { escola devem ser utilizados }\end{array}$ & $5,1 \%$ \\
\hline E. Uma combinação das anteriores & $26,9 \%$ \\
\hline F. Nenhuma das anteriores & $2 \%$ \\
\hline G. Não sei opinar & $10 \%$ \\
\hline
\end{tabular}

Fonte: Adaptado da SEDUC/SP, 2018. A última forneceu os microdados.

Quando as opiniões de todos os participantes da comunidade escolar são escutadas e consideradas, para os respondentes, expressa a melhor forma de garantir a GD na escola (33,6\%). Ressaltamos que outros 10\% não souberam ou quiseram se manifestar.

A tabela 4 indica as respostas dos participantes para a questão expressa no quadro 7.

\section{Tabela 4 - Respostas dos Participantes}

\begin{tabular}{|l|c|c|c|c|}
\hline $\begin{array}{l}\text { Na sua opinião, em que medida a GD pode melhorar os } \\
\text { seguintes aspectos do dia a dia da sua escola? }\end{array}$ & $\begin{array}{c}\text { Pode } \\
\text { melhorar } \\
\text { muito }\end{array}$ & $\begin{array}{c}\text { Pode } \\
\text { melhorar um } \\
\text { pouco }\end{array}$ & $\begin{array}{c}\text { Não pode } \\
\text { melhorar em } \\
\text { nada }\end{array}$ & $\begin{array}{c}\text { Não sei } \\
\text { opinar }\end{array}$ \\
\hline A inclusão e o respeito às diferenças entre as pessoas & $59,6 \%$ & $32,4 \%$ & $3,2 \%$ & $4,7 \%$ \\
\hline A motivação dos alunos para estudar & $65,8 \%$ & $28 \%$ & $2,9 \%$ & $3,2 \%$ \\
\hline A motivação dos alunos para participar do dia a dia da escola & $59,5 \%$ & $32,4 \%$ & $3,9 \%$ & $4,2 \%$ \\
\hline A aprendizagem dos alunos & $60,6 \%$ & $31,3 \%$ & $4,3 \%$ & $3,8 \%$ \\
\hline $\begin{array}{l}\text { O cuidado de professores, servidores, alunos e familiares } \\
\text { com a escola }\end{array}$ & $48,5 \%$ & $37,5 \%$ & $7,6 \%$ & $6,4 \%$ \\
\hline O envolvimento de todos no projeto pedagógico da escola & $48,5 \%$ & $36,2 \%$ & $5,9 \%$ & $9,5 \%$ \\
\hline A colaboração de todos na solução dos problemas da escola & $57,3 \%$ & $32,3 \%$ & $4,6 \%$ & $5,8 \%$ \\
\hline A aproximação entre as famílias e a escola & $50,8 \%$ & $33,7 \%$ & $8,8 \%$ & $6,8 \%$ \\
\hline $\begin{array}{l}\text { A preparação dos alunos para a cidadania e para a } \\
\text { participação em processos democráticos }\end{array}$ & $55,1 \%$ & $30,1 \%$ & $5 \%$ & $9,9 \%$ \\
\hline
\end{tabular}

Fonte: Adaptado de SEDUC/SP, 2018. A última forneceu os microdados. 
Em geral, podemos observar que a maioria dos respondentes possuem uma representação de que a GD pode melhorar muito "a inclusão e o respeito às diferenças entre as pessoas" (59,6\%); "a motivação dos alunos para estudar" (65,8\%); "a motivação dos alunos para participar do dia a dia da escola" (59,5\%); "a aprendizagem dos alunos" (60,6\%); "o cuidado de professores, servidores, alunos e familiares com a escola" (48,5\%); "o envolvimento de todos no projeto pedagógico da escola” (48,5\%); "a colaboração de todos na solução dos problemas da escola" (57,3\%); "a aproximação entre as famillias e a escola" (50,8\%); "a preparação dos alunos para a cidadania e para a participação em processos democráticos" (55,1\%).

Diante do exposto, os dados indicam que a maioria dos participantes acreditam que a democratização da gestão pode melhorar muitos aspectos do dia a dia da escola.

A tabela 5 indica as respostas dos participantes para a questão expressa no quadro 8 .

\section{Tabela 5 - Respostas dos Participantes}

\begin{tabular}{|l|c|c|c|c|}
\hline $\begin{array}{l}\text { Pensando no que contribui com a GD, você diria isso } \\
\text { sobre a sua escola? }\end{array}$ & Com certeza & $\begin{array}{c}\text { Mais ou } \\
\text { menos }\end{array}$ & Não diria & Não sei \\
\hline opinar & $59,6 \%$ & $32,4 \%$ & $3,2 \%$ & $4,7 \%$ \\
\hline As pessoas sabem o que é democracia & $22,6 \%$ & $63,6 \%$ & $6,3 \%$ & $7,5 \%$ \\
\hline $\begin{array}{l}\text { As pessoas se preocupam em decidir e fazer o que é melhor } \\
\text { para todos }\end{array}$ & $29,2 \%$ & $52,2 \%$ & $13,6 \%$ & $5 \%$ \\
\hline Os alunos têm orgulho, cuidam e participam da escola & $24,1 \%$ & $53,9 \%$ & $16,8 \%$ & $5,3 \%$ \\
\hline $\begin{array}{l}\text { A equipe gestora e os professores escutam e valorizam a } \\
\text { opinião dos alunos }\end{array}$ & $43,7 \%$ & $41,2 \%$ & $9,5 \%$ & $5,6 \%$ \\
\hline $\begin{array}{l}\text { A equipe gestora e os professores da escola ouvem e } \\
\text { estimulam a participação das familias dos alunos }\end{array}$ & $49,1 \%$ & $35 \%$ & $7,8 \%$ & $8,2 \%$ \\
\hline $\begin{array}{l}\text { As famílias têm interesse em participar da escola e da vida } \\
\text { escolar dos alunos }\end{array}$ & $29 \%$ & $54,6 \%$ & $9 \%$ & $7,4 \%$ \\
\hline $\begin{array}{l}\text { Os professores se interessam em participar das decisões } \\
\text { tomadas na escola }\end{array}$ & $56,8 \%$ & $31,1 \%$ & $3,8 \%$ & $8,3 \%$ \\
\hline $\begin{array}{l}\text { A escola promove atividades em parceria com outras } \\
\text { organizações do bairro }\end{array}$ & $27,6 \%$ & $31,9 \%$ & $21,8 \%$ & $18,7 \%$ \\
\hline $\begin{array}{l}\text { As pessoas da escola valorizam os espaços de participação, } \\
\text { como GE, CE e APM }\end{array}$ & $43,3 \%$ & $36,7 \%$ & $9,4 \%$ & $10,7 \%$ \\
\hline $\begin{array}{l}\text { A Secretaria de Educação cria condições para que a gestão } \\
\text { democrática aconteça na escola }\end{array}$ & $35,9 \%$ & $36 \%$ & $10,1 \%$ & $18,1 \%$ \\
\hline
\end{tabular}

Fonte: Adaptado de SEDUC/SP, 2018. A última forneceu os microdados. 
Podemos constatar que a maioria dos participantes indicaram "mais ou menos" como resposta para as afirmações: "as pessoas sabem o que é democracia" $(63,6 \%)$; "as pessoas se preocupam em decidir e fazer o que é melhor para todos" $(52,2 \%)$; "os alunos têm orgulho, cuidam e participam da escola" (53,9\%); "as famílias têm interesse em participar da escola e da vida escolar dos alunos" (54,6\%); "a escola promove atividades em parceria com outras organizações do bairro" (31,9\%); "a Secretaria de Educação cria condições para que a gestão democrática aconteça na escola" (36\%).

A resposta "com certeza", foi indicada pela maioria dos participantes nas afirmações: "a equipe gestora e os professores escutam e valorizam a opinião dos alunos" (43,7\%); "a equipe gestora e os professores da escola ouvem e estimulam a participação das famílias dos alunos" (49,1\%); "os professores se interessam em participar das decisões tomadas na escola" (56,8\%); "as pessoas da escola valorizam os espaços de participação, como CE, APM e GE” (43,3\%).

De modo geral, notamos que a maioria dos participantes reforça a ideia de que a valorização da opinião e a participação das famílias em órgãos colegiados contribuem com o desenvolvimento da GD.

\section{REFLEXÕES A PARTIR DOS DADOS DA PESQUISA}

Esta descrição e apresentação dos dados do projeto permite-nos chamar a atenção para alguns pontos que, no nosso entendimento, deverão ser considerados em um processo de avaliação de projetos educacionais.

Um primeiro ponto diz respeito à complexidade que envolve a avaliação de um projeto. Entendemos a avaliação como uma prática social que não pode ser reduzida a uma questão técnica. O projeto tem, essencialmente, uma natureza política. Isto, por certo, não significa que não se possa/deva avaliar projetos de políticas públicas. Ao contrário, toda a literatura neste campo (JANUZZI, 2002; LOTTA, 2018; DRAIBE, 2001; ARRETCHE, 2001; FIGUEIREDO; FIGUEIREDO, 1986; dentre outros) vem se esforçando para nos ensinar os caminhos (técnicos) para se produzir uma avaliação política da política (pública). Mas, não se trata de uma ferramenta puramente técnica, como se a própria política fosse, antes de tudo, um processo técnico de tomada de decisões.

A avaliação da política educacional levou-nos a outra questão: que escala de análise adotar no estudo? Salientamos que a nossa opção pela micro, é, na realidade, uma opção que confere visibilidade ao fenômeno e, não define, portanto, a escala de análise. Logo, o nosso objeto de estudo exige um movimento entre as escalas micro e macro. 
Também chamamos a atenção para o fato de o debate em políticas educacionais demandar de análises dos condicionantes sociais, culturais, históricos, econômicos e políticos que incidem nos processos de formulação e regulação do campo. O contexto em que se inscreve o nosso estudo, grosso modo, indica estarmos diante de contradições.

Vamos pensar na sociedade em que vivemos: a sociedade capitalista. Estamos imersos em condicionantes que reproduzem um modo de conhecer, de fazer, de conviver e de ser, relacionados à organização capitalista. Logo, a conjuntura histórica atual repõe os elementos estruturais, que reelaboram os conteúdos com o propósito de permanecer formatando as pessoas, segundo esse paradigma.

Apesar de não ser o foco da pesquisa, um dos achados complementa a ideia anterior, que aponta que a SEDUC/SP desenvolve o referido projeto em parceria com o Instituto Inspirare. Como já destacamos a inquietude, voltamos a perguntar: por que a Secretaria ocultou essa informação no site oficial?

Não tem sido por acaso, a criação de parcerias entre organizações privadas e os sistemas estaduais de educação. A lógica revela a tentativa de desresponsabilização do Estado e evidencia, em muitos casos, a transferência de recursos públicos para o setor privado (PERONI, 2010; ADRIÃO, 2015). A pesquisa coordenada por Adrião (2015) mapeou a inserção do setor privado nas redes estaduais de educação no período de 2005-2015 e um dos resultados aponta que 353 organizações, a maioria recebendo dinheiro público, atuam em 26 Estados e no Distrito Federal.

O projeto Gestão Democrática da Educação, implantado em 2016, parece seguir essa mesma lógica de parcerias. A SEDUC/SP, em parceria com o Instituto Inspirare, do qual o Porvir faz parte, desenvolveu o projeto que, surgiu para atender as determinações do PNE (BRASIL, 2014) e do PEESP (SÃO PAULO, 2016), além de demandas dos envolvidos pela ampliação do diálogo. A relação que promovemos entre este acordo ou parceria e uma concepção de transferência de recursos públicos para instituições privadas para a execução de tarefas que cabem ao Estado realizar advém do silêncio ou falta de informações públicas pela SEDUC/SP acerca do tal acordo. Isto é, por que a própria Secretaria Estadual não conduziu o projeto, ou por que não buscou parcerias, por exemplo, com as equipes de pesquisadores que atuam neste campo nas universidades estaduais de São Paulo?

Outro ponto direciona-se para a questão semântica. Para exemplificar, tomaremos apenas a expressão "GD”, aspecto central de nosso estudo. 
Qual/is o/s sentido/s empregado/s à GD? Há, pelo menos, dois projetos em disputa, que por vezes se inter-relacionam e até se confundem, dadas as características próprias dos sistemas e dos sujeitos. Trata-se das concepções de GD e de gestão gerencial. Desta forma, nos vemos diante de dois sentidos empregados à GD ou, diante do mesmo sentido com modus operandi diferentes? Sabemos da necessidade de aprofundamento dessa questão, porém, ao que nos parece, a confusão pode provocar a mescla de elementos das duas concepções no cotidiano escolar. De toda sorte, recentemente, observamos um avanço do projeto neoliberal no país, dificultando o avanço do exercício democrático.

A GD na/da educação pública é princípio constitucional e, no Brasil, temos uma proliferação de experiências interessantes e exitosas nesta direção, desde práticas escolares (DIÓGENES; GOMES, 2013; SANTOS; PRADO, 2018), passando pela gestão de sistemas municipais ou estaduais de ensino (GUTIERREZ; MENDES, 2016; SOARES; CARDOZO, 2018; ESQUINSANI, 2016; SOUZA; PIRES, 2018) e, inclusive, na condução da macropolítica educacional nacional, por meio, por exemplo das Conferências Nacionais de Educação (SOUZA, 2016; DOURADO et al, 2016).

Contudo, a gestão escolar e educacional tem sido tensionada, e isto parece ocorrer de tempos em tempos na história da administração escolar no Brasil (SOUZA, 2007a), por movimentos e tentativas de inserção de práticas e processos tecnocráticos na condução da educação e das escolas, os quais são (quase) sempre uma tentativa de inserir na escola as "boas" práticas gerenciais, adotadas via de regra pela engenharia e gestão de negócios, como mostram os estudos de Newman; Clarke (2012), Drabach; Souza (2014), Sisto (2018) e Nascente el al (2018), dentre outros. Esta tensão parece avançar contra elementos da GD, com o argumento de que ao invés de ampla participação e discussão com a comunidade escolar na lida com os problemas educacionais e institucionais das escolas, há uma "forma ótima" de administrá-las, no gerenciamento de técnicas e insumos que garantem o alcance de resultados mensuráveis nos índices estaduais e nacional de desempenho escolar.

A questão aqui é que o projeto da SEDUC/SP encerra uma contradição: de um lado articula uma ampla parte da sociedade ao promover a escuta de suas representações sobre a GD e, ao mesmo tempo, conduz uma política educacional com baixa participação e diálogo com a sociedade na identificação, planejamento, enfrentamento e avaliação dos problemas educacionais e escolares no Estado.

Mas, de toda forma, compreendendo que tais contradições compõem os movimentos próprios da política (SOUZA, 2016; MAINARDES, 2018), cumprenos, nesta pesquisa, analisar o discurso sobre a ação. Mais especificamente, é importante reforçar que o nosso estudo se baseia nas "práticas declaradas" pelos 
sujeitos no projeto, disponibilizadas no site da SEDUC/SP. Isso indica que os dados revelam o discurso da ação e não a ação em si. Também, esses dados foram organizados pela SEDUC/SP, que não ofereceram com detalhes o itinerário da pesquisa por ela realizada.

Diante o exposto, constatamos que o projeto apresentou: (a) um grande número de participações; (b) o maior número absoluto de respondentes é composto por alunos; (c) a representatividade maior foi a dos gestores; (d) a maior parte dos participantes pertence aos Anos Finais do Ensino Fundamental; (e) a maior parte dos participantes foram os jovens; (f) a participação em espaços democráticos é bastante baixa.

A partir dos resultados, foi possível extrair alguns indícios que nos levam à aproximação das representações dos sujeitos sobre a GD:

- o diálogo entre a equipe gestora e todos que fazem parte da escola foi a opção que melhor descreveu a GD: isto é ilustrativo e importante. Os respondentes compreendem um elemento basilar da GD, o diálogo, como a sua característica mais emblemática. O diálogo é tanto a razão da democracia quanto sua ferramenta, ou seja, o intuito da gestão escolar democrática é colocar as pessoas em processos comunicativos dialógicos (PINTO, 1994) e, ao mesmo tempo, para que a democracia ocorra é preciso disposição dos sujeitos a interagirem dialogadamente uns com os outros (TOURAINE, 1996);

- quando as opiniões da comunidade escolar são escutadas e consideradas foi a opção que melhor indicou a forma de garantir a GD na escola: decorrente da compreensão da centralidade do diálogo na GD, o reclame pela condição de escuta, ou seja, de que efetivamente as diferentes posições e concepções sejam ouvidas e levadas em conta nos processos de tomada de decisão, mas também na identificação de problemas e no acompanhamento e avaliação da escola, é algo central para os sujeitos da pesquisa;

- para a questão, em que medida a GD pode melhorar: "a inclusão e o respeito às diferenças entre as pessoas"; "a motivação dos alunos para estudar"; "a motivação dos alunos para participar do dia a dia da escola"; "a aprendizagem dos alunos"; "o cuidado de professores, servidores, alunos e familiares com a escola"; "o envolvimento de todos no projeto pedagógico da escola"; "a colaboração de todos na solução dos problemas da escola”; "a aproximação entre as famílias e a escola"; "a preparação dos alunos para a cidadania e para a participação em processos democráticos", a maioria dos respondentes indicou que pode melhorar muito. Isto traz um componente inédito e que precisa ser melhor estudado no Brasil, que relaciona a GD com o ensino e com a aprendizagem estudantil. Alguns poucos estudos (SOUZA, 2007b; 2019) se debruçaram sobre a questão, 
mas ainda há muito campo e variáveis a se explorarem nesta temática. De toda forma, é relevante que a comunidade inquirida reconheça que há relação entre as condições de GD e os resultados do trabalho pedagógico;

- para a questão, pensando no que contribui com a GD, você diria que na/a sua escola: "as pessoas sabem o que é democracia"; "as pessoas se preocupam em decidir e fazer o que é melhor para todos"; "os alunos têm orgulho, cuidam e participam da escola"; "as famílias têm interesse em participar da escola e da vida escolar dos alunos"; "promove atividades em parceria com outras organizações do bairro", a maioria dos respondentes indicou que nem sempre é possível responder assertivamente. Isto também é interessante, na medida em que o público inquerido consegue perceber os limites sobre o domínio que a própria população tem sobre o que é a democracia. Escapa aos limites deste trabalho, mas é possível levantar a hipótese de que esta compreensão emerge justamente do fato de que aqueles que mais participam da vida escolar e social são justamente os que participam também de levantamentos desta natureza;

- ainda para a questão, pensando no que contribui com a GD, você diria que na sua escola: "a equipe gestora e os professores escutam e valorizam a opinião dos alunos"; "a equipe gestora e os professores da escola ouvem e estimulam a participação das famílias dos alunos"; "os professores se interessam em participar das decisões tomadas na escola"; "as pessoas da escola valorizam os espaços de participação, como CE, APM e GE”, a maioria dos respondentes indicou "com certeza" como resposta. Aqui temos uma resposta já esperada, uma vez que dificilmente os respondentes diriam que os dirigentes escolares e os professores não promovem a participação democrática nas escolas, especialmente porque não sabem até que ponto o professor ou diretor não irá ter acesso aos dados do questionário. Algo equivalente já foi encontrado pela literatura (SOUZA, 2007a). Por outro lado, assim como no ponto anterior, é possível supor que esta posição seja decorrente justamente do perfil dos respondentes de enquetes como esta;

- somente na questão, pensando no que contribui com a GD, você diria que "a Secretaria de Educação cria condições para que a GD aconteça na escola", a indicação dos respondentes ficou equilibrada entre "mais ou menos" e "com certeza": o que confirma, em alguma proporção, nosso argumento no tópico anterior, mas, como há docentes respondentes, e eles compõem um segmento politicamente organizado e engajado, é possível supor que aqueles que tenderam a relativizar as certezas sobre o apoio democrático da SEDUC/SP sejam os professores. A base de dados, contudo, não permite tal grau de desagregação das informações para se confirmar ou infirmar tal hipótese. 


\section{CONSIDERAÇÕES FINAIS}

Este artigo analisou o conteúdo geral das representações dos sujeitos sobre a GD da escola pública, a partir da análise dos dados compilados dos questionários aplicados pela SEDUC/SP.

Muito se tem pesquisado e escrito sobre a organização da escola, no entanto, apesar de os estudos mostrarem experiências interessantes, as práticas de gestão pouco têm contribuído para o alcance de sua democratização. No nosso entendimento, é preciso que os sujeitos da escola comecem a perceber que as formas de participação apregoadas pelo Estado colocam o termo democracia como um simples adjetivo da gestão, retirando, com isso, o seu verdadeiro sentido, que é político-pedagógico 4 .

Daí a necessidade de se construir um projeto de educação e de escola que garanta o desmantelamento da hierarquização de poder, um projeto pautado em relações de poder que retirem do Estado a exclusividade do comando da educação e o compartilhe com a comunidade e com os sujeitos que constroem as escolas cotidianamente.

Baseado nas representações dos sujeitos no referido projeto, observamos que ainda há uma distância entre o discurso e a ação. Apesar de a maioria acreditar que a GD pode melhorar vários aspectos da educação escolar, os estudos mencionados anteriormente evidenciam que a participação em espaços escolares democráticos é bastante baixa. Esse continua sendo um dos entraves para a efetivação da GD da escola pública, qual seja, a compreensão de que todos e cada um devemos assumir nosso lugar na esfera pública, seja na escola, seja na sociedade. Entendemos que essa situação reflete o contexto político da sociedade atual, na qual espera-se do outro a participação ativa e a luta por mudanças, mas sem que isto represente necessariamente a sua própria participação ativa.

Em síntese, as práticas declaradas parecem pouco contribuir com o processo de democratização da gestão das escolas públicas, mas algumas representações podem nos trazer algum alento, ou melhor, podem servir como um ponto de partida. $\mathrm{O}$ fato de os respondentes perceberem o diálogo como elemento central da democracia, e a associarem com a edificação de condições de aprendizagem, é algo a ser considerado, ainda que insuficiente, especialmente se observarmos as condições concretas e objetivas de conversão desta representação em ação.

4 Para maior aprofundamento desta discussão, ver Souza (2012). 
Apontamos para a necessidade de se questionar as condições concretas e objetivas das quais a GD (não) se realiza pelas razões expostas, isto é, entendemos que seja primordial a revisão dos simbolismos da participação, para que ocorra a redefinição das relações de poder. É preciso buscarmos a efetiva partilha do poder, o que implica, necessariamente, a participação dos sujeitos da escola na tomada de decisões, mas antes e além, na constituição de espaços de diálogo para a identificação de problemas e para o acompanhamento e avaliação das ações e políticas escolares e educacionais.

Saviani (2012, p. 36) afirma que "[..] quando mais se falou em democracia no interior da escola, menos democrática foi a escola; e quando menos se falou em democracia, mais ela esteve articulada com a construção de uma ordem democrática”. Apesar dessa avaliação vincular-se ao período da Escola Nova, ela parece aplicar-se à conjuntura atual.

Assim, nossa avaliação final em relação ao projeto da SEDUC/SP é que ele levanta informações que são potencialmente interessantes para se traçar o perfil dos sujeitos e processos democráticos nas escolas estaduais paulistas, mas, dada a conjuntura e a história recente da política educacional no Estado, não é exagerado afirmar que se tratou mais de uma resposta às exigências legais do que, efetivamente, de um projeto em favor da democratização da escola pública.

\section{REFERÊNCIAS}

ADRIÃO, T. (coord.). Mapeamento da inserção do setor privado nas redes estaduais de educação (2005-2015). Campinas, Greppe, 2015.

ARRETCHE, M. Uma contribuição para fazermos avaliações menos ingênuas. In: BARREIRA, M. C. R. N.; CARVALHO, M. do C. B. (orgs.). Tendências e Perspectivas na Avaliação de Políticas e Programas Sociais. São Paulo: IEE/ PUC, 2001.

BRASIL. Lei $\mathbf{n}^{\mathbf{0}} \mathbf{1 3 . 0 0 5}$, de 25 de junho de 2014. Aprova o Plano Nacional de Educação e dá outras providências. Brasília, 2014.

DIÓGENES, E. M. N; GOMES, M. G. C. Participação dos pais e alunos no cenário da gestão democrática. Educação: Teoria e Prática. Rio Claro, vol. 23, n. 44, p. 112-129, set./dez. 2013. 
DOURADO, L. F; GROSSI JUNIOR, G.; FURTADO, R. A. Monitoramento e avaliação dos planos de educação: breves contribuições. RBPAE, v. 32, n. 2, p. 449-461, mai./ago. 2016.

DRABACH, N. ; SOUZA, A. R. Leituras sobre a gestão democrática e o gerencialismo na/da gestão da educação no Brasil. Rev. Pedagógica (Unochapecó), v. 16, n. 33, p. 221-248, jul./dez. 2014.

DRAIBE, S. Avaliação de implementação: esboço de uma metodologia de trabalho em PP. In: BARREIRA, M. C. R. N.; CARVALHO, M. do C. B. (orgs.). Tendências e Perspectivas na Avaliação de Políticas e Programas Sociais. São Paulo: IEE/PUC, 2001.

ESQUINSANI, R. S. S. Contribuições ao debate sobre gestão democrática da educação: foco em legislações municipais sul-rio-grandenses. RBEP. Brasília, v. 97, n. 247, p. 490-505, set./dez. 2016.

FIGUEIREDO, M.; FIGUEIREDO, A. C. Avaliação Política e Avaliação de Políticas: um quadro de referência teórica. Rev. Fundação João Pinheiro, p. 108-129, 1986.

GANZELI, P. Reforma Administrativa da Secretaria Estadual de Educação de São Paulo (2011), Programa Ensino Integral (2012): administração pública gerencial em processo. Exitus. Santarém, vol. 9, n. 3, p. 33-58, jul./set. 2019.

GUTIERREZ, D. V. G.; MENDES, O. C. A gestão da educação em municípios do Pará a partir da adesão ao Plano de Ações Articuladas (PAR). Educação em Questão. Natal, v. 54, n. 42, p. 161-189, set./dez. 2016.

JANUZZI, P. M. Uso, mau uso e abusos de indicadores sociais na formulação e avaliação de políticas públicas municipais. Rev. Adm. Pública. Rio de Janeiro, v. 36, n. 1, p. 51-72, jan./ fev. 2002.

LOTTA, G. S. Burocracia, redes sociais e interação: uma análise da implementação de políticas públicas. Rev. Sociol. Polit., v. 26, n. 66, p. 145-173, jun. 2018.

MAINARDES, J. Reflexões sobre o objeto de estudo da política educacional. Laplage em Revista. Sorocaba, v. 4, n. 1, p. 186-201, jan./abr. 2018. 
MARANGONI, R. A. Gestão Democrática: a busca pela implantação na escola pública. Rev. Administração Educacional. Recife, v. 9, n.1, p. 05-22, jan./jun. 2018.

MOSCOVICI, S. A psicanálise, sua imagem e seu público. Trad. Sonia Fuhrmann. Petrópolis: Vozes, 2012.

NASCENTE, R. M. M.; CONTI, C. L. A.; LIMA, E. F. Políticas públicas e formas de gestão escolar: relações escola-Estado e escola-comunidade. Rev. FAEEBA Ed. e Contemp., Salvador, v. 27, n. 53, p. 157-169, set./dez. 2018.

NEWMAN, J.; CLARKE, J. Gerencialismo. Educ. Real., Porto Alegre, v. 37, n. 2, p. 353-381, maio/ago. 2012.

PERONI, V. M. V. A democratização da educação em tempos de parcerias entre o público e o privado. Rev. Educ. Públ. Cuiabá, v. 19, n. 40, p. 215-227, mai./ ago. 2010.

PINTO, J. M. R. Administração e liberdade: um estudo do conselho de escola à luz da ação comunicativa de Jürgen Habermas. Tese de Doutorado (Educação). Campinas: UNICAMP, 1994.

SÃO PAULO (Estado). Lei $\mathbf{n}^{\mathbf{0}} \mathbf{1 6 . 2 7 9}$, de 8 de julho de 2016. Aprova o Plano Estadual de Educação de São Paulo e dá outras providências. São Paulo, 2016.

SÃO PAULO (Estado). Gestão Democrática da Educação. São Paulo: SEDUC/SP, 2016. Disponível em: <http://www.educacao.sp.gov.br>. Acesso em 04 jan. 2018.

SANTOS, I. M.; PRADO, E. C. Entre a eleição e a indicação política: as relações de poder no cotidiano do gestor escolar. Exitus. Santarém, vol. 8, n. 1, jan./abr. 2018.

SAVIANI, D. Escola e Democracia. 42 ed. Campinas: Autores Associados, 2012. 
SISTO, V. Managerialismo, autoritarismo y la lucha por el alma de la gestión: el caso de las últimas reformas en políticas de dirección escolar en Chile. Rev. FAEEBA - Ed. e Contemp., Salvador, v. 27, n. 53, p. 141-156, set./dez. 2018.

SOARES, E. L.; CARDOZO, M. J. P. B. A gestão democrática nos marcos legais de municípios do estado do Maranhão: uma análise das leis dos Conselhos Municipais de Educação. Práxis Educativa. Ponta Grossa, v. 13, n. 1, p. 181-201, jan./abr. 2018.

SOUZA, A. R. Perfil da Gestão Escolar no Brasil. Tese de Doutorado (Educação: História, Política, Sociedade). São Paulo: PUC-SP, 2007 a.

As relações entre os resultados da avaliação e os modelos de gestão escolar. Intermeio. Campo Grande, v. 13, n. 25, p. 64-81, 2007 b.

A natureza política da gestão escolar e as disputas pelo poder na escola. Rev. Brasileira de Educação, v. 17, n. 49, jan./abr. 2012.

- Políticas de democratização da gestão educacional no Brasil: experiência e expectativa com o novo Plano Nacional de Educação. Rev. Pedagógica (Unochapecó), v. 18, n. 39, p. 111-128, set./dez. 2016.

- As condições de democratização da gestão da escola pública brasileira. Ensaio. Rio de Janeiro, v. 27, n. 103, p. 271-290, abr./jun. 2019.

.; PIRES, P. A. G. As leis de gestão democrática da Educação nos estados brasileiros. Educar em Revista. Curitiba, v. 34, n. 68, p. 65-87, mar./ abr. 2018.

TOURAINE, A. O que é democracia? Trad. Guilherme João de Freitas Teixeira. Petrópolis: Vozes, 1996. 


\section{Ricardo Alexandre Marangoni}

Doutor em Educação (UMESP). Professor do Programa de Pós-Graduação em Educação e do Programa de Mestrado Profissional em Formação de Gestores Educacionais, ambos da Universidade Cidade de São Paulo (UNICID), Pesquisador Associado do Centro Internacional de Estudos em Representações Sociais e Subjetividade - Educação da Fundação Carlos Chagas (CIERS-ed/ FCC) e Pós-Doutorando em Educação pela Universidade Federal do Paraná (UFPR).E-mail: ramarangoni@hotmail.com

\section{Ângelo Ricardo de Souza}

Doutor em Educação (PUC/SP). Professor e Pesquisador do Núcleo de Políticas Educacionais (NuPE) e do Programa de Pós-Graduação em Educação (PPGE) da Universidade Federal do Paraná (UFPR). E-mail: angelo@ufpr.br

Recebido em: 19/06/2020

Aceito em: 21/10/2020 